\title{
Article \\ Polyacrylonitrile Nanofibers Containing Viroblock as Promising Material for Protective Clothing
}

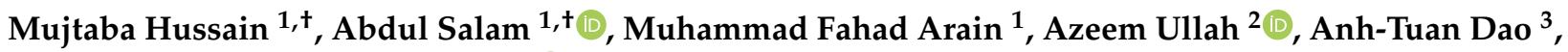 \\ Hai Vu-Manh ${ }^{3}$, Duy-Nam Phan ${ }^{3, *}$ D, Aamir Shabbir Ansari ${ }^{4}$, Muhammad Qamar Khan ${ }^{1, *}$, Zafar Javed 5 \\ and Ick-Soo Kim $2, *$ (D)
}

1 Nanotechnology Research Group, Department of Textile \& Clothing, Faculty of Engineering and Technology, National Textile University Karachi Campus, Karachi 74900, Pakistan; 15fm333d@shinshu-u.ac.jp (M.H.); ab.salam@ntu.edu.pk (A.S.); muhammadfahad@ntu.edu.pk (M.F.A.)

2 Nano Fusion Technology Research Group, Institute for Fiber Engineering (IFES), Interdisciplinary Cluster for Cutting Edge Research (ICCER), Shinshu University, Tokida 3-15-1, Ueda 386-8567, Nagano, Japan; 08tex101@gmail.com

3 School of Textile—Leather and Fashion, Hanoi University of Science and Technology, Hanoi 10000, Vietnam; tuan.daoanh@hust.edu.vn (A.-T.D.); hai.vumanh@hust.edu.vn (H.V.-M.)

4 Alkaram Textile Mills Pvt. Ltd., Karachi 75120, Pakistan; aamir.ansari@alkaram.com

5 Department of Design, School of Art \& Design, National Textile University, Faisalabad 37610, Pakistan; zafar@ntu.edu.pk

* Correspondence: nam.phanduy@hust.edu.vn (D.-N.P.); qamarkhan154@gmail.com (M.Q.K.); kim@shinshu-u.ac.jp (I.-S.K.)

$\dagger$ Both authors have equal contribution.

check for updates

Citation: Hussain, M.; Salam, A.; Arain, M.F.; Ullah, A.; Dao, A.-T.; Vu-Manh, H.; Phan, D.-N.; Ansari, A.S.; Khan, M.Q.; Javed, Z.; et al. Polyacrylonitrile Nanofibers Containing Viroblock as Promising Material for Protective Clothing. Appl Sci. 2021, 11, 11469. https://doi.org/ 10.3390/app112311469

Academic Editor: Sergio Torres-Giner

Received: 9 November 2021

Accepted: 1 December 2021

Published: 3 December 2021

Publisher's Note: MDPI stays neutral with regard to jurisdictional claims in published maps and institutional affiliations.

Copyright: (c) 2021 by the authors. Licensee MDPI, Basel, Switzerland. This article is an open access article distributed under the terms and conditions of the Creative Commons Attribution (CC BY) license (https:/ / creativecommons.org/licenses/by/ $4.0 /)$.
Abstract: Antimicrobial viroblock/polyacrylonitrile nanofiber webs fabricated using the electrospinning method were assessed in terms of the antimicrobial activity against infectious agents as a potential material used in mask production. Viroblock (VB) is an amalgam of lipid vesicle and silver. Lipid vesicle depletes the virus outer membrane, which contains cholesterol, while silver ions penetrate the virus, interact with sulfur-bearing moieties, and possess the virus bactericidal property. VB, having anti-coronavirus and anti-influenza properties, was prepared in four different concentrations, $0.5 \mathrm{wt} \%, 1 \mathrm{wt} \%, 1.5 \mathrm{wt} \%$, and $2 \mathrm{wt} \%$, in regard to nanofiber weight. The resultant nanofibers were characterized by scanning electron microscope (SEM), Fourier transform infrared (FTIR), thermogravimetric analysis (TGA), water contact angle, water content, and thermogravimetric analysis (TGA). Moreover, all nanofibrous samples were evaluated for cell proliferation assay and ATCC antibacterial tests. Based on characterization results and cytotoxicity, the developed composite nanofibers-based webs showed good promise for utilization in anti-viral masks. Particularly, $2 \mathrm{wt} \%$ $\mathrm{VB} / \mathrm{PAN}$ nanofibers have the highest antibacterial properties against negative and positive bacteria along with excellent cell viability.

Keywords: antimicrobial; antiviral; viroblock; nanofibers; cell viability

\section{Introduction}

The outbreak of the severe acute respiratory syndrome coronavirus 2 (SARS-COV-2 or COVID-19) in Wuhan in 2019 is a global health emergency with many cases of death and huge economic losses [1]. The worldwide health crisis has affected all sectors of life and spread at a rapid pace. An unprecedented challenge is upon the scientific world to find effective medical treatments for the disease. COVID-19 infections are transmitted mainly through the inhalation of droplets produced by coughing and sneezing [2]. The droplets of variable sizes are dispersed through the air or rest on varied material surfaces. Droplets more than $20 \mu \mathrm{m}$ easily fall onto objects, and viruses from these droplets have been reported to last anywhere from a few hours up to several days on plastic, glass, stainless steel, cardboard, and clothing surfaces. Smaller droplets of less than $10 \mu \mathrm{m}$ are 
capable of airborne transmission; particularly, droplets less than $1 \mu \mathrm{m}$ can linger in the air for more than $12 \mathrm{~h} \mathrm{[3].} \mathrm{Recent} \mathrm{research} \mathrm{suggested} \mathrm{that} \mathrm{the} \mathrm{airborne} \mathrm{transmission} \mathrm{of}$ COVID-19 is the primary propagating route, similar to previous SARS-CoV1.

Before a vaccine is commonly accessed, wearing facial masks as a safety procedure is recommended by health organizations and governments to curb the rapid spread of the COVID-19 disease [4]. Nanofibrous membranes can be used as an effective protective layer against the coronavirus disease due to tiny pore sizes and high air permeability. Microand nanofiber masks have been developed recently with reusable, particle filtering, and antiviral properties by immobilizing antivirus agents [5]. With suitable polymer materials and disinfectants, masks can have recyclable properties and can prevent transmission of aerosol droplets with microbes after several washing cycles. Thus, exploiting active compounds and infusing them into nanofibrous masks are an efficient virus inactivation system [6].

Recently, electrospun nanofibers have been a hot topic due to their versatility and straightforwardness [7]. Productivity has largely increased in several countries including Japan, China, the USA, and Korea with the applications of multi-nozzles and other techniques [8]. The nanofibers have a wide range of morphologies and diameters, from micro- to nanometer; particularly, random orientation and porosity have the potential to capture the virus. Moreover, controllable pore size gives easy passing for water vapors. The characteristics of electrospun membranes are a high surface area, controllable porosity, and pore size [9]. Thus, the applications have been exploited in varied fields including water and air filters, tissue engineering, medical machines, environmental engineering, drug delivery, and energy storage [10]. A nanofiber-based filter with excellent capture efficiency and high blocking ability against fine dust, bacteria, and viruses shows promise in mass-produced face masks [11,12].

Polyacrylonitrile (PAN) nanofibers obtain advantages of spinnability and excellent mechanical properties. PAN nanofibers have been used extensively for various applications such as filtration and carbon fiber mass-production [13]. PAN-based carbon fibers account for $90 \%$ of all worldwide production [14]. Nanoscale PAN membranes can be used for mask applications with easily tuned pore size, porosity, and hydrophilicity. PAN also exhibits particularly good thermal stability, solvent resistance, and good mechanical properties, and has been employed for carrying bioactive agents for antibacterial applications. PAN electrospun nanofibers, in the range of a few hundred nanometers, are promising air filters with breathable properties and filterability against viruses and fine particles [15].

Viroblock is a combination of aliphatic lipidic chains and particular cyclodextrins, which can deplete the cholesterol present in viral membranes. The silver penetration then inhibits the viral replication and kills bacteria and viruses. Testing VB on facemasks demonstrated the 4-log reduction between treated and untreated samples, with long lasting effects on different products including curtains, surgical gowns, masks, and air filters. The 4-log reduction in H1N1, H5N1, coronavirus, and other respiratory syncytial viruses proved the potency of this active compound [16]. Herein, we present a facile route to facilitate the distribution of VB in the PAN polymer matrix. With different ratios of VB and PAN to fabricate antimicrobial webs, we aimed to investigate the relation between the loading amounts of VB and the antibacterial activities and the cytotoxicity against mouse fibroblast.

\section{Materials and Methods}

\subsection{Materials}

Polyacrylonitrile (PAN, analytical grade), dimethylformamide (DMF, analytical grade) were purchased from Sigma Aldrich Corporation, St. Louis, MO, USA. Viroblock was provided by Heiq, a subsidiary of a parent company, Swiss specialty chemistry company, Materials AG Ruetistrasse 128952 Schlieren (Zurich), Switzerland. 


\subsection{Preparation of $V B / P A N$ Nanofibers}

In DMF, $10 \mathrm{wt} \%$ PAN was the constant concentration used for all solutions. The polymer was dissolved in DMF and the solution was gently stirred for $3 \mathrm{~h}$. The VB was used in the PAN prepared solution in four different concentrations, such as neat Pan, $0.5 \% w / w \mathrm{VB} / \mathrm{PAN}, 1 \% w / w \mathrm{VB} / \mathrm{PAN}, 1.5 \% w / w \mathrm{VB} / \mathrm{PAN}$, and $2 \% w / w \mathrm{VB} / \mathrm{PAN}$. The spinning solution was injected into a needle syringe that had a metal needle attached with an inner diameter of $0.6 \mathrm{~mm}$. There was a $140 \mathrm{~mm}$ distance between the collector and the tip of the needle. A total of $13 \mathrm{kV}$ was applied on the positive electrode and the nanofibers were collected on the negative one. The resultant VB/PAN nanofiber webs were used for fabricating antiviral and antibacterial protective clothing such as face masks.

\subsection{Characterization}

\subsubsection{Morphology Analysis}

The morphology of PAN nanofibers and VB/PAN nanofibers was investigated by scanning electron microscopy (SEM, S-3000N, Hitachi Co., Tokyo, Japan) at $10 \mathrm{kV}$ accelerating voltage. The average diameter of the PAN nanofibers and VB/PAN nanofibers was determined by analyzing the SEM images, using the Image J software version 1.49, measuring the diameter of 50 nanofiber strands.

\subsubsection{Chemical State Analysis}

Fourier transform infrared (FTIR-ATR) spectra were recorded between the wavelengths of $400-4000 \mathrm{~cm}^{-1}$ using an IR Prestige-21 (Shimadzu Co., Ltd., Kyoto, Japan) and studied for the chemical interactions between PAN and VB, with a resolution of $4 \mathrm{~cm}^{-1}$ and a cumulative addition of 128 scans.

\subsubsection{Water Contact Angle and Water Content}

The water contact angle was calculated to reflect the hydrophilicity of the composite nanofibers. The values of water contact angle were calculated statically using a contact angle meter (Digidrop, GBX, Romans-sur-Isère, France). After 5 measurements, the values were expressed as an average with standard deviation.

For the water content, nanofibrous specimens were cut into $1 \times 1 \mathrm{~cm}$ pieces. They were weighed before being immersed in deionized water for $1 \mathrm{~h}$. After that, the specimens were removed and placed on adsorptive papers to discard all dripping water. The water content was calculated as follows:

$$
\text { Water content }(\%)=\frac{\left(W_{w}-W_{d}\right)}{W_{w}} \times 100
$$

where $W_{w}$ and $W_{d}$ were the weight of the wet nanofibers and dried ones, respectively.

\subsubsection{TGA Study}

The thermal behavior of PAN nanofibers, VB/PAN nanofibers, and the confirmed presence of $\mathrm{VB}$ in the VB/PAN nanofibers were investigated by Thermo Gravimetric Analysis. It was performed on the thermo-plus TG-8120 (Rigaku Corporation, Osaka, Japan). The measurement was carried out in a static mode under air temperature at a heating rate of $10^{\circ} \mathrm{C} / \mathrm{min}$, with the temperature range of $0-600{ }^{\circ} \mathrm{C}$.

\subsubsection{In Vitro Assessment}

To examine the cell attachment performance of PAN and VB/PAN nanofibers, an MTT study was performed for nine days in mouse fibroblast line L929, and was repeated in triplicate for each sample. After being sterilized, each nanofibrous specimen was immersed in a well containing DMEM-F12 medium with $10 \%$ FBS. The L929 cells were then seeded on each sample with a density of 16,000 cells $/ \mathrm{cm}^{2}$. On the day of the test, $50 \mu \mathrm{L}$ of medium culture containing Thiazolyl Blue Tetrazolium Bromide (MTT; $5 \mathrm{mg} / \mathrm{mL}$ ) was added to each well. The specimens with cells were incubated at $37{ }^{\circ} \mathrm{C}$ with $5 \% \mathrm{CO}_{2}$ for a further $12 \mathrm{~h}$. 
After that, the samples were removed and washed with PBS. Formosan crystals of live cells were dissolved completely in $400 \mu \mathrm{L}$ DMSO. Subsequently, $200 \mu \mathrm{L}$ of supernatant solution was transferred into the 96-well plate and the absorbance was measured at $570 \mathrm{~nm}$. To calibrate the dye absorption, control samples without cells were soaked in a medium culture with the addition of MTT, then washed with PBS, and soaked in DMSO before the absorbance of the control was acquired at $570 \mathrm{~nm}$. For the evaluation of the cell viability, the absorbance of each well was subtracted by the control.

\subsubsection{Air Permeability Analysis}

To investigate the air permeability of the PAN and VB/PAN nanofibers, AirPerm model M021A, manufactured by SDL Atlas (Rock Hill, SC, USA), was implemented following ASTM D737.

\subsubsection{Antibacterial Activity}

To investigate the antibacterial properties of PAN nanofibers and VB/PAN nanofibers against Escherichia coli (E. coli) and Staphylococcus aureus (S. aureus) bacteria, the antibacterial activities were determined using the Kirby-Bauer method. The nanofiber samples of $10 \mathrm{~mm}$ diameter were placed for investigation on agar plates seeded with bacterial cells in the log phase and incubated at $37^{\circ} \mathrm{C}$ for $16 \mathrm{~h}$. All the samples were repeated three times using different specimens. The diameter of the inhibition zone was examined using Image J 1.50i software.

\section{Results and Discussion}

\subsection{Morphology Analysis}

SEM analysis was used to investigate the surface morphology of PAN electrospun nanofibers loaded with four different concentrations of VB. The prepared fibers were analyzed at a magnification of 3000 with a working voltage of $10 \mathrm{kV}$. It can be seen in Figure 1 that there is a smooth formation of electrospun nanofibers in all cases without the presence of any beads in all prepared samples.
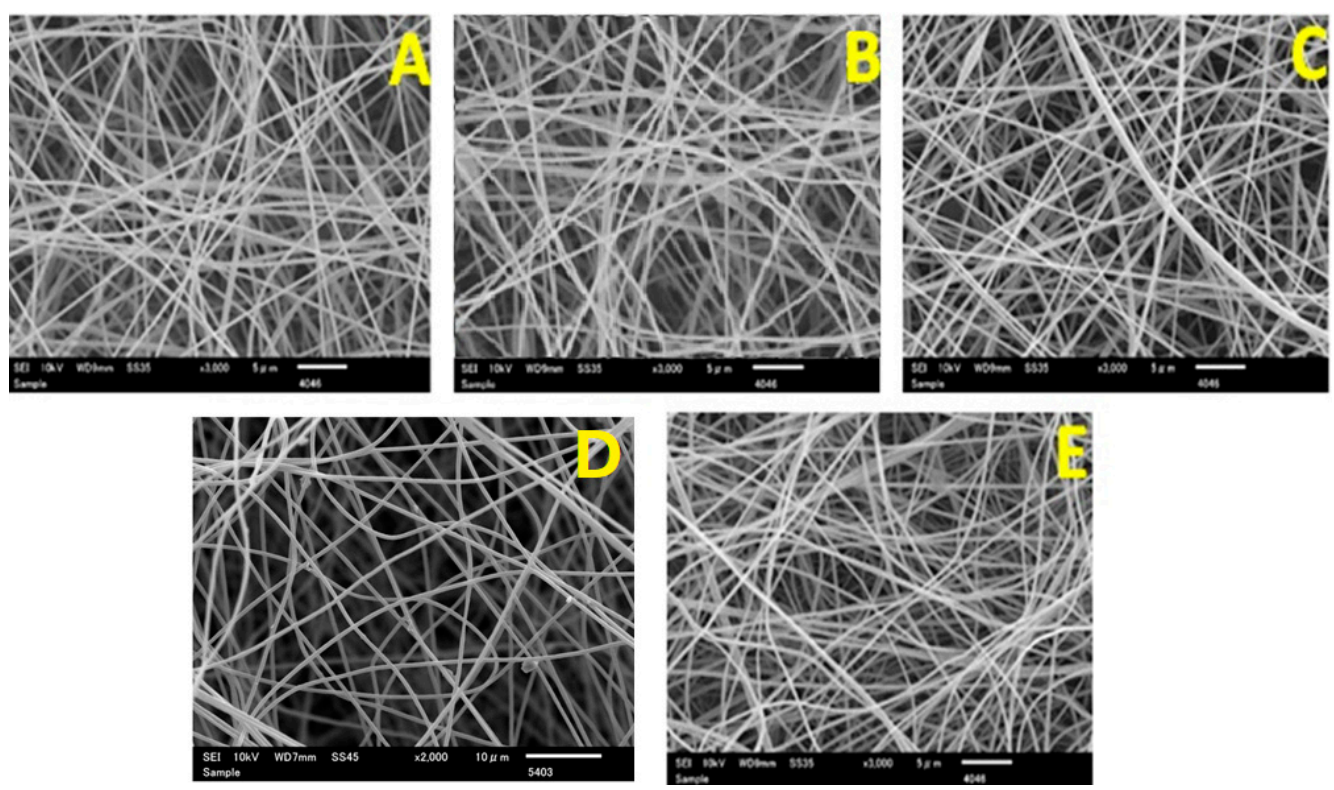

Figure 1. Surface morphology of prepared electrospun nanofibers: (A) pure PAN, (B) $0.5 \%$ VB PAN, (C) $1 \%$ VB PAN, (D) $1.5 \%$ VB PAN, and (E) $2 \%$ VB PAN.

To determine the average diameter of electrospun nanofibers, Image J software was used to measure 50 different values from different areas of each prepared sample and the histogram was plotted to determine the average diameter of the prepared samples. In Figure 2, the horizontal axis indicated the diameter of electrospun nanofibers, while 
the vertical axis expressed the diameter distribution percentage. It was found that in the case of pure PAN electrospun nanofibers, the distribution curve showed that the average diameter of the nanofibers was $373.40 \pm 49.80 \mathrm{~nm}$. In Figure 2B, the PAN electrospun nanofibers loaded with $0.5 \% \mathrm{VB}$ had an average diameter of $366.55 \mathrm{~nm}$, with a standard deviation value of $49.55 \mathrm{~nm}$. Similarly, the histograms in the cases of $1 \%, 1.5 \%$, and $2 \%$ VBloaded PAN electrospun nanofibers indicated that the average diameters of the nanofibers were $381.52 \pm 63.53,341.17 \pm 62.10$, and $361.76 \pm 55.67 \mathrm{~nm}$, respectively, as shown in Figure 2C-E.
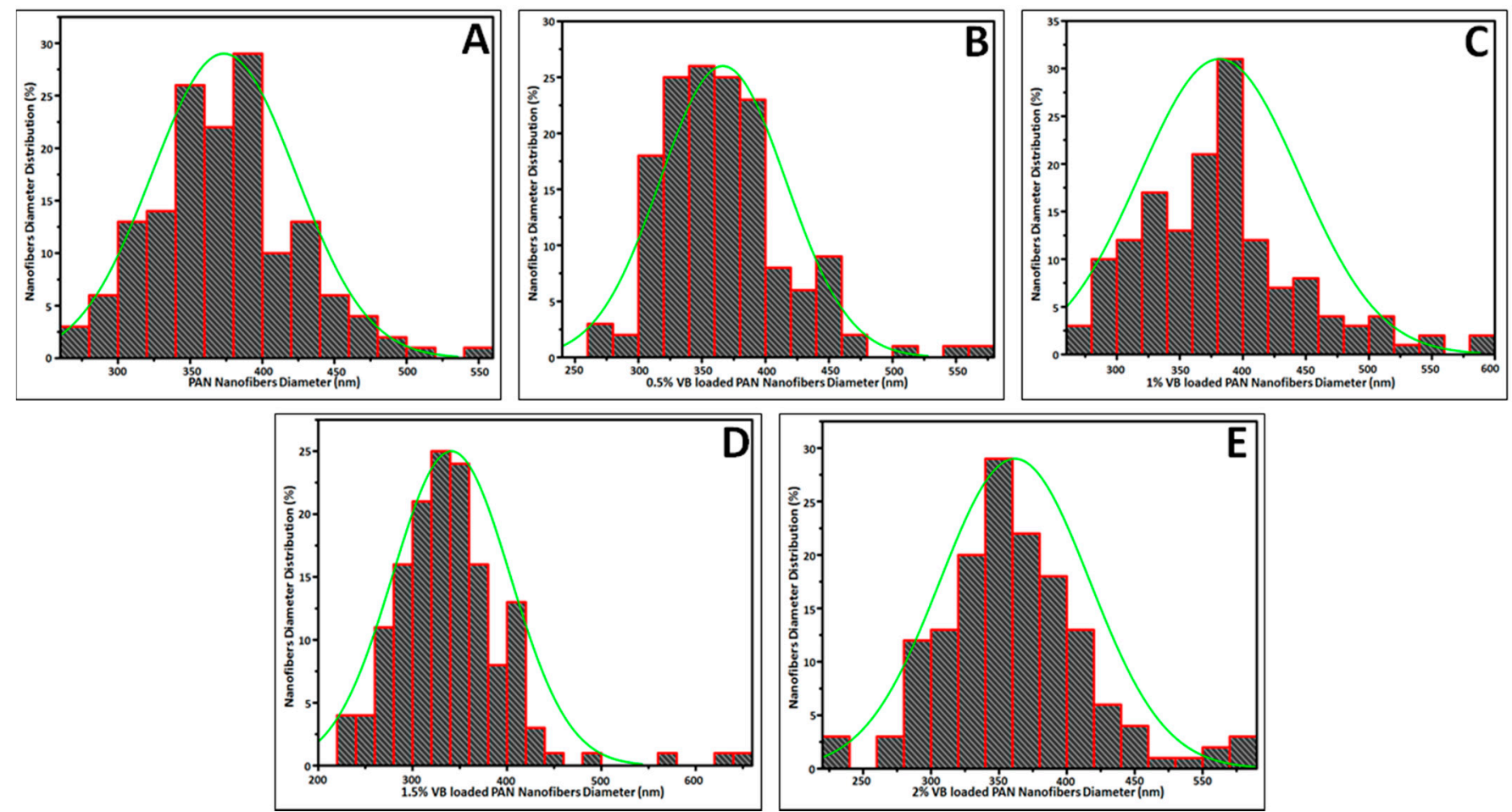

Figure 2. Diameter distribution curve: (A) pure PAN, (B) $0.5 \% \mathrm{VB} / \mathrm{PAN},(\mathbf{C}) 1 \% \mathrm{VB} / \mathrm{PAN},(\mathrm{D}) 1.5 \% \mathrm{VB} / \mathrm{PAN},(\mathrm{E}) 2 \%$ VB/PAN.

\subsection{Chemical Interactions Analysis}

FTIR spectra were used to analyze the chemical groups of the prepared electrospun nanofibers. Figure 3 shows the FTIR spectra of pure PAN nanofibers, 0.5\% VB-loaded PAN nanofibers, $1 \%$ VB-loaded PAN nanofibers, 1.5\% VB-loaded PAN nanofibers, and $2 \%$ VB-loaded PAN nanofibers. The spectral range varies from $1000 \mathrm{~cm}^{-1}$ to $3500 \mathrm{~cm}^{-1}$. In all spectra, there was broadband appearing in the range of $3000 \mathrm{~cm}^{-1}$ to $3500 \mathrm{~cm}^{-1}$ due to the presence of $-\mathrm{OH}$ group, belonging to moisture absorbed. In all spectra, the vibrational peak appeared at $2242 \mathrm{~cm}^{-1}$ ascribed to the presence of the nitrile $(-\mathrm{C} \equiv \mathrm{N})$ functional group. In the case of pure PAN electrospun nanofibers, the peaks that appeared at $2884 \mathrm{~cm}^{-1}$ and $2943 \mathrm{~cm}^{-1}$ indicated the stretching and bending of the methyl functional group [17,18]. The peaks present at $1732 \mathrm{~cm}^{-1}$ and $1453 \mathrm{~cm}^{-1}$ corresponded to the carboxylic functional group of PAN. The peak that emerged at $1170 \mathrm{~cm}^{-1}$ was attributed to (-C-O) stretching due to the formation of aliphatic ether. The peaks that appeared at $1224 \mathrm{~cm}^{-1}, 1360 \mathrm{~cm}^{-1}$, and $1593 \mathrm{~cm}^{-1}$ were ascribed to the (-C-O) stretching and -OH bending, respectively [14,19]. The other four spectra were similar to that of the PAN spectrum with little variation in peak position. This is because the silver nanoparticles and other compounds that were present in the VB integrated into PAN, forming the composite material. In the case of $0.5 \%$ VB-loaded PAN electrospun nanofibers, a characteristic peak appeared at $1181 \mathrm{~cm}^{-1}$ corresponding to $\mathrm{C}-\mathrm{O}$ stretching, the medium peak appeared at $1422 \mathrm{~cm}^{-1}$ representing the $-\mathrm{O}-\mathrm{H}$ bending, and the peak at $1450 \mathrm{~cm}^{-1}$ was due to the $-\mathrm{C}-\mathrm{H}$ bending. The peak at $1597 \mathrm{~cm}^{-1}$ was 
attributed to $-\mathrm{N}-\mathrm{H}$ bending due to the formation of the amine group [20]. The stretching of $1656 \mathrm{~cm}^{-1} \mathrm{C}=\mathrm{C}$ was due to the conjugated alkene. The peak at $1728 \mathrm{~cm}^{-1}$ represented the carboxylic functional group as a result of the oxidation of PAN reacting with VB. In the case of $1 \%$ VB-loaded PAN electrospun nanofibers, the characteristic peaks appear at $1174 \mathrm{~cm}^{-1}$ and $1197 \mathrm{~cm}^{-1}$, corresponding to -C-O stretching. The peaks that appeared at $1452 \mathrm{~cm}^{-1}$, $2882 \mathrm{~cm}^{-1}$, and $2914 \mathrm{~cm}^{-1}$ represented -C-H stretching of methyl functional group from VB. In the spectrum of $1 \%$ VB-loaded PAN, the medium peak emerged at $1391 \mathrm{~cm}^{-1}$, corresponding to -C-N stretching, which was due to aromatic amine of VB. The peaks at $1653 \mathrm{~cm}^{-1}$ and $1731 \mathrm{~cm}^{-1}$ were ascribed to the carboxylic functional groups [21]. In the case of $1.5 \%$ VB-loaded PAN electrospun nanofibers, the peaks present at $1073 \mathrm{~cm}^{-1}$ and $1172 \mathrm{~cm}^{-1}$ corresponded to -C-O stretching of VB. The peak that emerged at $1453 \mathrm{~cm}^{-1}$ was due to the $-\mathrm{CH}$ methyl functional group. The peak at $1733 \mathrm{~cm}^{-1}$ represented the carboxylic functional group of oxidized PAN. A similar spectrum was obtained in the case of 2\% VB-loaded PAN electrospun nanofibers and a shift in characteristic peaks was also observed. The peaks that appeared at $1042 \mathrm{~cm}^{-1}, 1122 \mathrm{~cm}^{-1}$, and $1170 \mathrm{~cm}^{-1}$ were caused by the -C-O stretching of the secondary alcohol and aliphatic ether, respectively. The formation of phenol was demonstrated by the -OH bending, observed in the spectrum at $1316 \mathrm{~cm}^{-1}$ and $1415 \mathrm{~cm}^{-1}$. - $\mathrm{CH}$ bending was observed at $1455 \mathrm{~cm}^{-1}, 2852 \mathrm{~cm}^{-1}$, and $2922 \mathrm{~cm}^{-1}$ due to the methyl functional group of VB. The peak at $1738 \mathrm{~cm}^{-1}$ was ascribed to the carboxylic functional group of oxidized PAN [22,23].

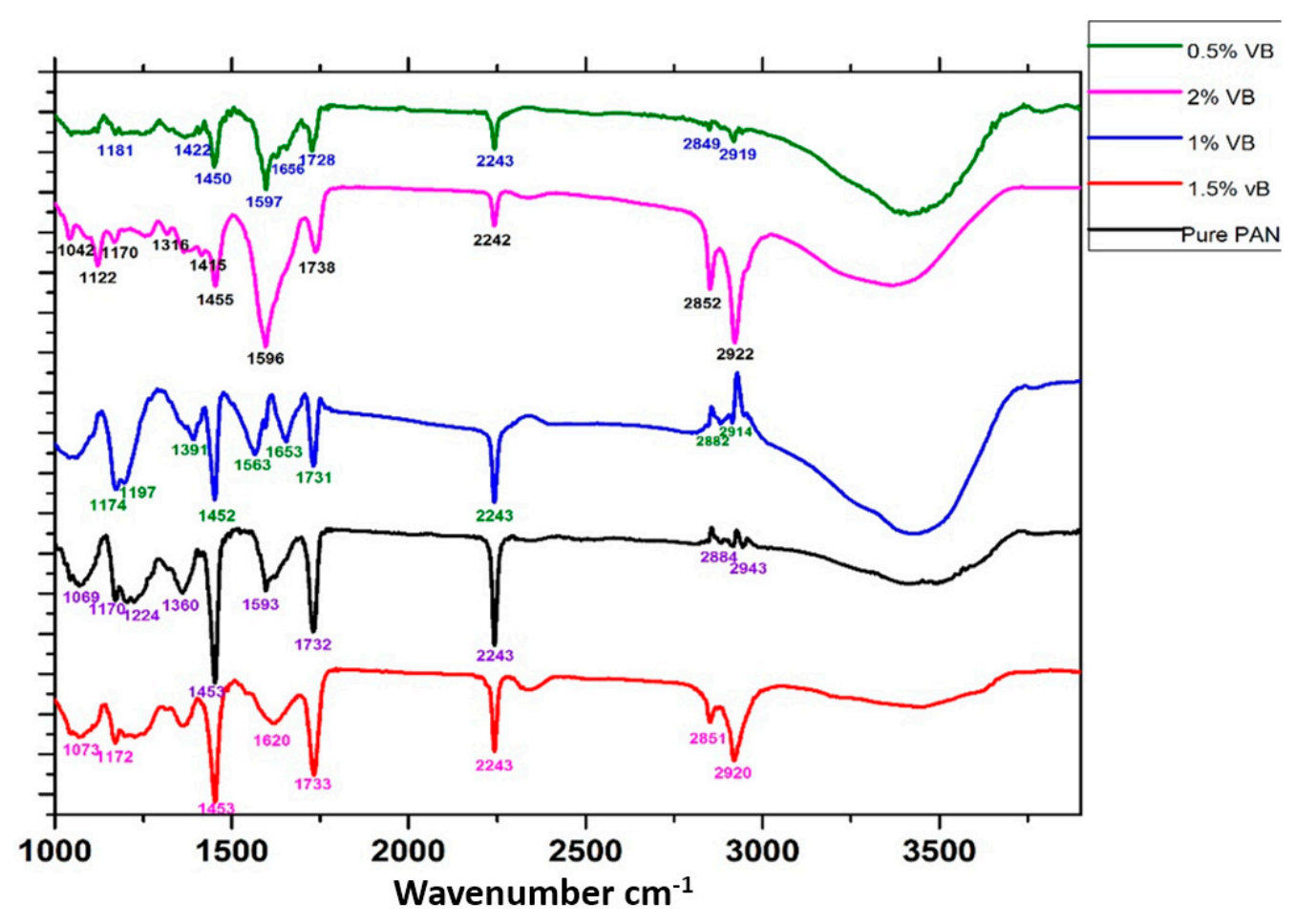

Figure 3. FTIR analysis of prepared electrospun nanofibers.

\subsection{Water Content and Water Contact Angle Study}

COVID-19 is a highly infectious disease with the symptoms of fever, dry cough, weakness, and even respiratory failure in some severe cases. Masks are still the main protection to block water spatter and droplets from breath, cough, and sneezing of COVID-19 patients, and thus avoid virus transmission. Hydrophobic and anti-droplet properties are important characteristics in face masks; these attributes could be achieved by a coating or chemical modification of mask materials [24]. The water repellency or hydrophilicity was affirmed by water content and water contact angle, which are key parameters influencing the fouling propensity of a membrane. It was observed that the water content values were not affected by the incorporation of VB in the PAN nanofibers, as shown in Figure 4a. In addition to 
water content, the nanofiber-based web was characterized by the water contact angle. The static water contact angle measurement was performed to investigate the wetting properties of membrane surfaces. The water contact angle $\theta$ of all samples was less than $90^{\circ}$ and all prepared membranes were considered hydrophilic [25]. Conversely, the material surface was accepted as hydrophobic when the contact angle was larger than $90^{\circ}[26,27]$. As shown in Figure $4 \mathrm{~b}$, the water contact angles of PAN and VB/PAN were $73.9^{\circ}, 77.4^{\circ}, 72.6^{\circ}$, $78.3^{\circ}$, and $74.2^{\circ}$ for PAN, $0.5 \% \mathrm{VB} / \mathrm{PAN}, 1 \% \mathrm{VB} / \mathrm{PAN}, 1.5 \% \mathrm{VB} / \mathrm{PAN}$, and $2 \% \mathrm{VB} / \mathrm{PAN}$, respectively, exhibiting no recognizable difference, which again confirmed that there was no significant influence of adding VB into the surface wettability of all membranes.

(a)

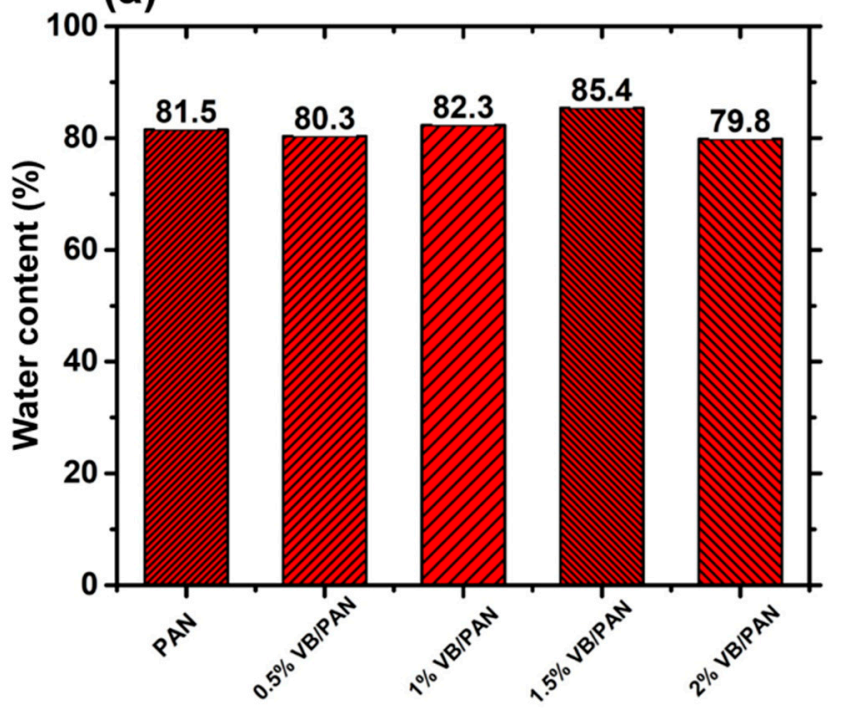

(b)

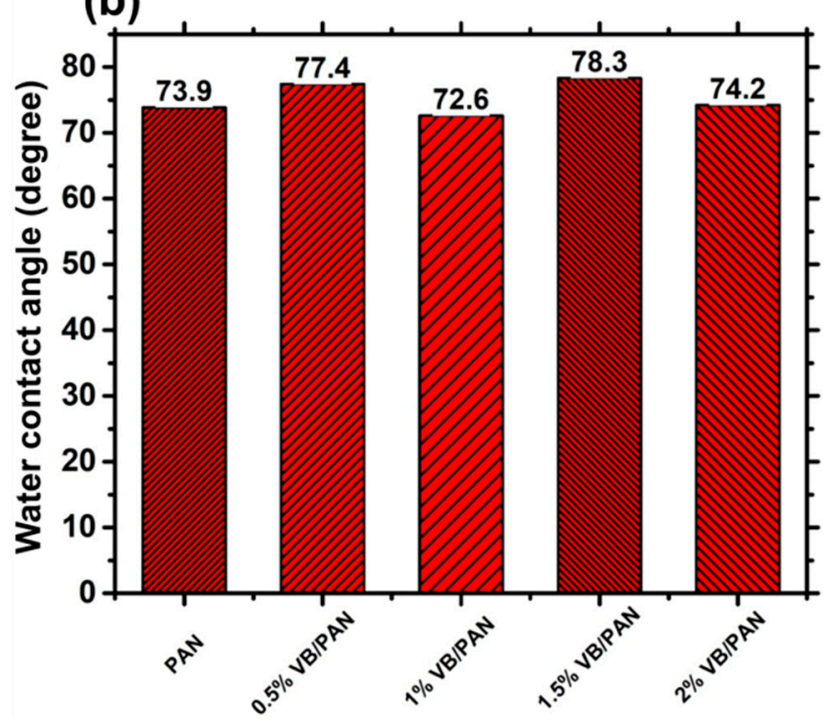

Figure 4. Hydrophilic behaviors of PAN and VB/PAN nanofibers (a) Water content and (b) Water contact angle.

\subsection{TGA Study}

The thermal degradation behaviors of PAN nanofibers and VB/PAN nanofibers were recorded using TGA. To ensure good reproducibility, all specimens were prepared with a weight of $10.0 \pm 1.0 \mathrm{mg}$. It was operated in a static mode under normal air temperature with a heating rate of $10^{\circ} \mathrm{C} / \mathrm{min}$ and a temperature range from 0 to $500^{\circ} \mathrm{C}$. Figure 5 shows the dependence of weight retaining of PAN nanofibers with varied VB loading concentrations and temperature. It was observed that the weight residue percentages of $\mathrm{VB} / \mathrm{PAN}$ nanofibers increased as the higher concentration of $\mathrm{VB}$ were loaded in the VB/PAN nanofibers. The trend was explained by the amounts of Ag presented in VB and $\mathrm{Ag}$ was thermally stable in this range of temperature. TGA spectra also confirmed the presence of VB in the VB/PAN nanofiber-based web because $2 \% \mathrm{VB} / \mathrm{PAN}$ nanofibers had $32 \%$ weight residue compared to neat PAN nanofibers, whose weight residue was much lower at $18 \%$.

\subsection{In Vitro Assessment}

In order to examine the toxicity of PAN nanofibers and VB/PAN nanofibers in tissue engineering applications, an MTT analysis was implemented, as shown in Figure 6. An MTT study was performed up to 9 days using mouse fibroblast L929 and was repeated in triplicate for each sample. With the increasing concentrations of VB, the cells were observed to be more viable with higher absorbent values of accumulated formazan in DMSO. The MTT reduced formazan crystals in living cells and the formazan amount was directly proportional to the living cell quantity. Cell viability of all nanofibers gradually increased with time progression, revealing the suitability of the scaffolds for metabolic activity and cell proliferation. It was also confirmed that when the concentration of VB was increased, the cell viability was increased, as shown in Figure 6, demonstrating that 
VB-loaded PAN nanofibers were non-toxic and had potential in soft tissue engineering. The MTT analysis confirmed that the resultant nanofiber webs can be used as protective clothing for COVID-19 due to their non-toxicity for fibroblast cells.

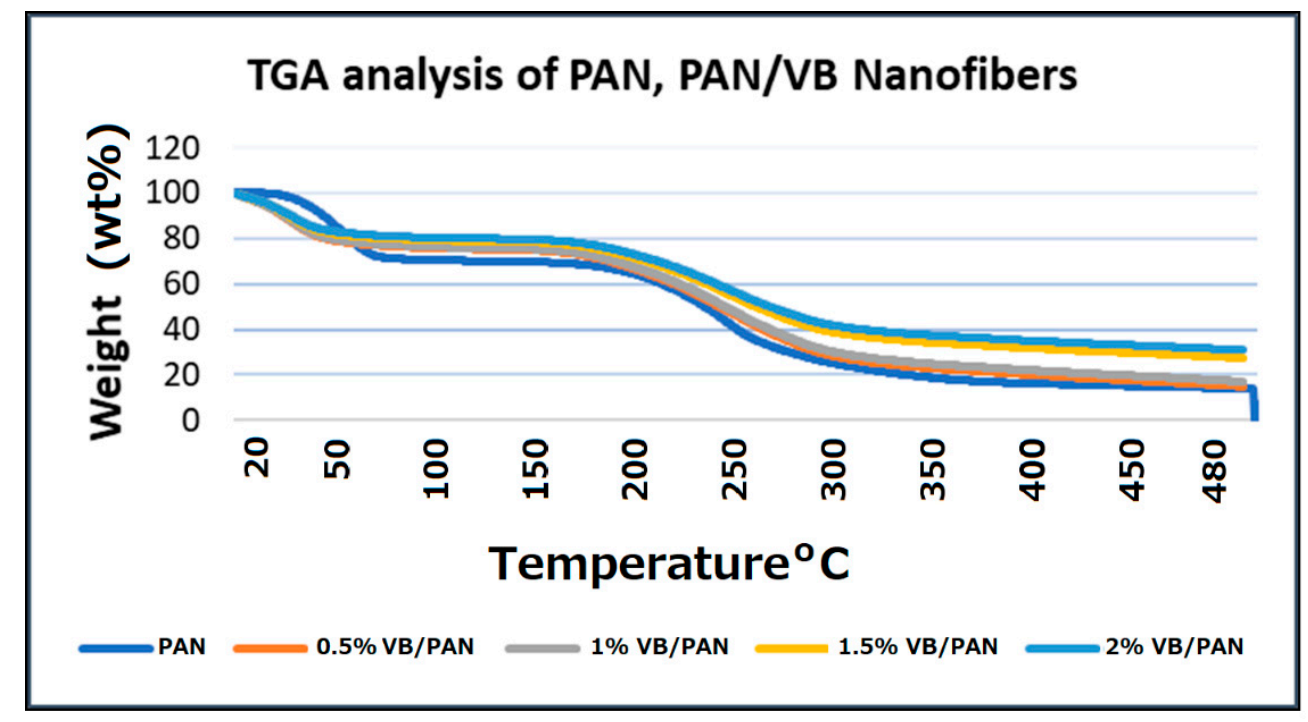

Figure 5. TGA spectra of PAN and VB/PAN nanofibers.

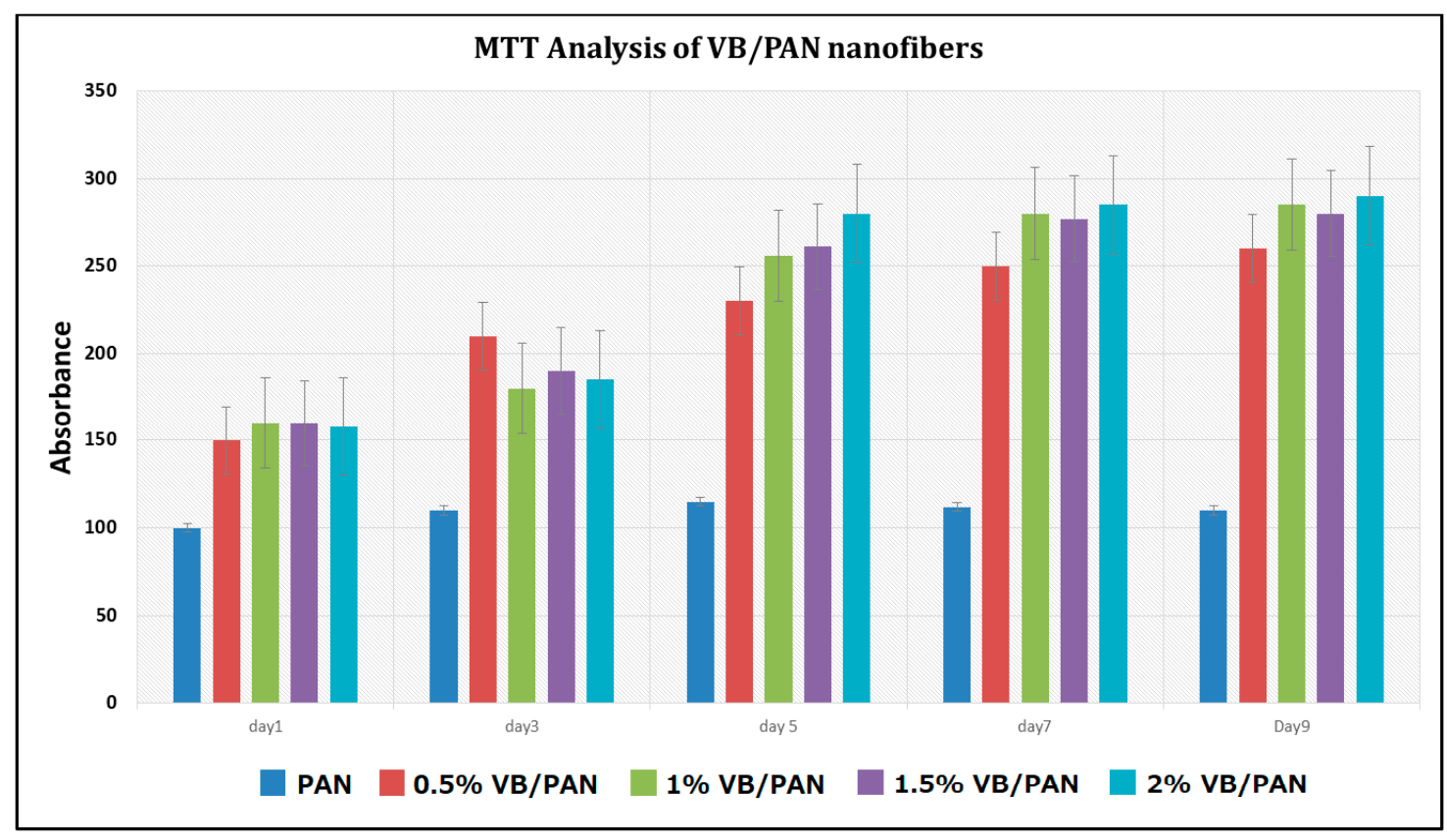

Figure 6. In vitro assessment of PAN and VB/PAN nanofibers.

\subsection{Antibacterial Activity of VB-Loaded PAN Nanofibers}

The antibacterial activity of PAN nanofibers loaded with four different dosages of VB was analyzed for antibacterial activity against Gram-positive and Gram-negative bacterial strains by using the disc diffusion method. Figure 7 shows the antibacterial images of VBloaded PAN nanofibers. The activity against $S$. aureus was more pronounced in comparison to E. coli. The possible reason could be that the cell membrane of E. coli was relatively thicker than that of S. aureus. 


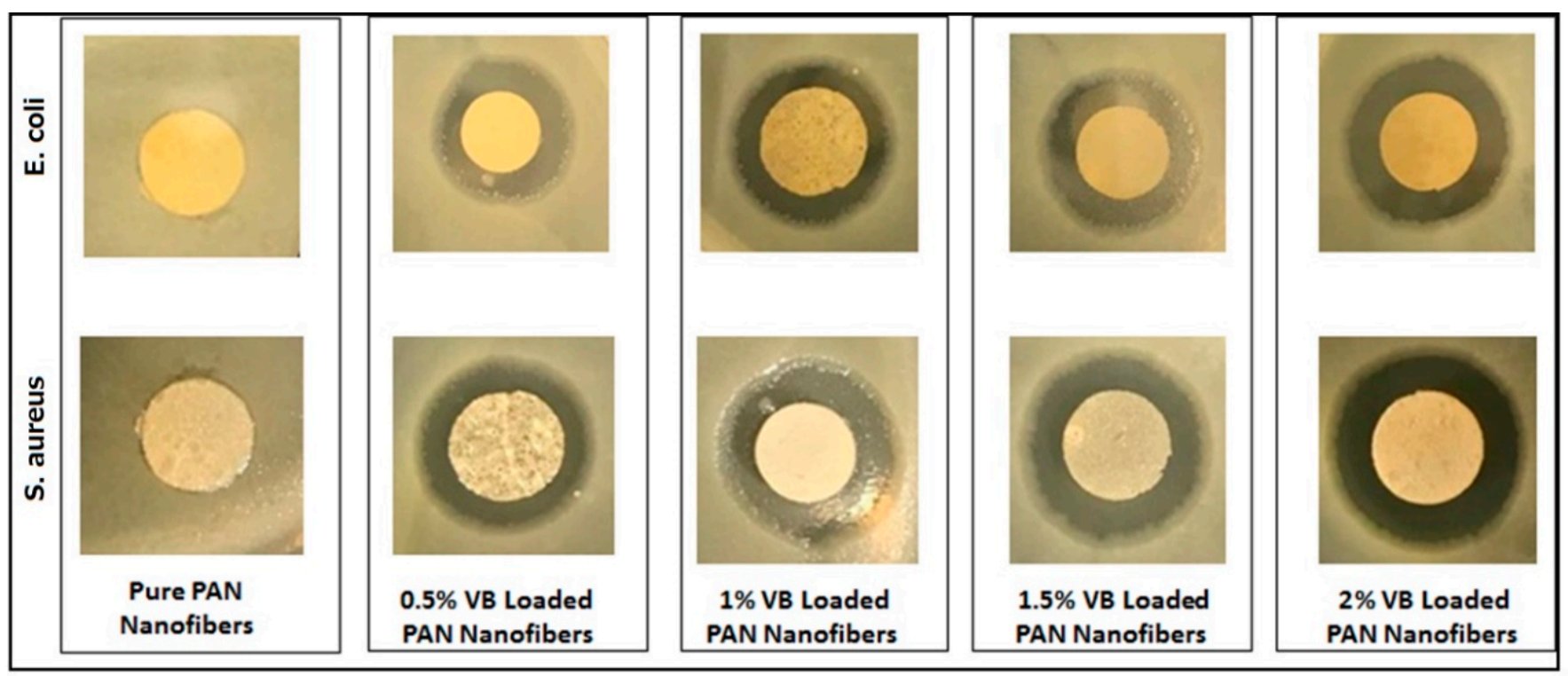

Figure 7. Antibacterial activity of VB-loaded PAN electrospun nanofibers against E. coli and S. aureus bacteria.

The zone of inhibition was calculated using Image J software by measuring the clear area around the nanofiber specimens. Figure 8 shows the histogram of the results. The values of the inhibition zone against $S$. aureus bacteria were 15.3, 15.7, 16.0, and $16.8 \mathrm{~mm}$ corresponding to $0.5 \%, 1 \%, 1.5 \%$, and $2 \%$ VB-loaded PAN nanofibers, respectively. Similarly, in the case of E. coli bacteria, the values of the halo zone were 13.5, 14.85, 15.15 , and $15.65 \mathrm{~mm}$. VB mechanisms of E. coli and $S$. aureus termination were bacterial membrane perturbation and damage inflicted by vesicle and the ROS generated by nano silver intracellularly disturbing the functionality of DNA, enzymes, and protein. After the disruption of the bacterial membranes, silver penetrated the bacterial cells, interacting with sulfur-containing proteins and thiol groups of enzymes, causing impaired functionality and DNA damage [28].

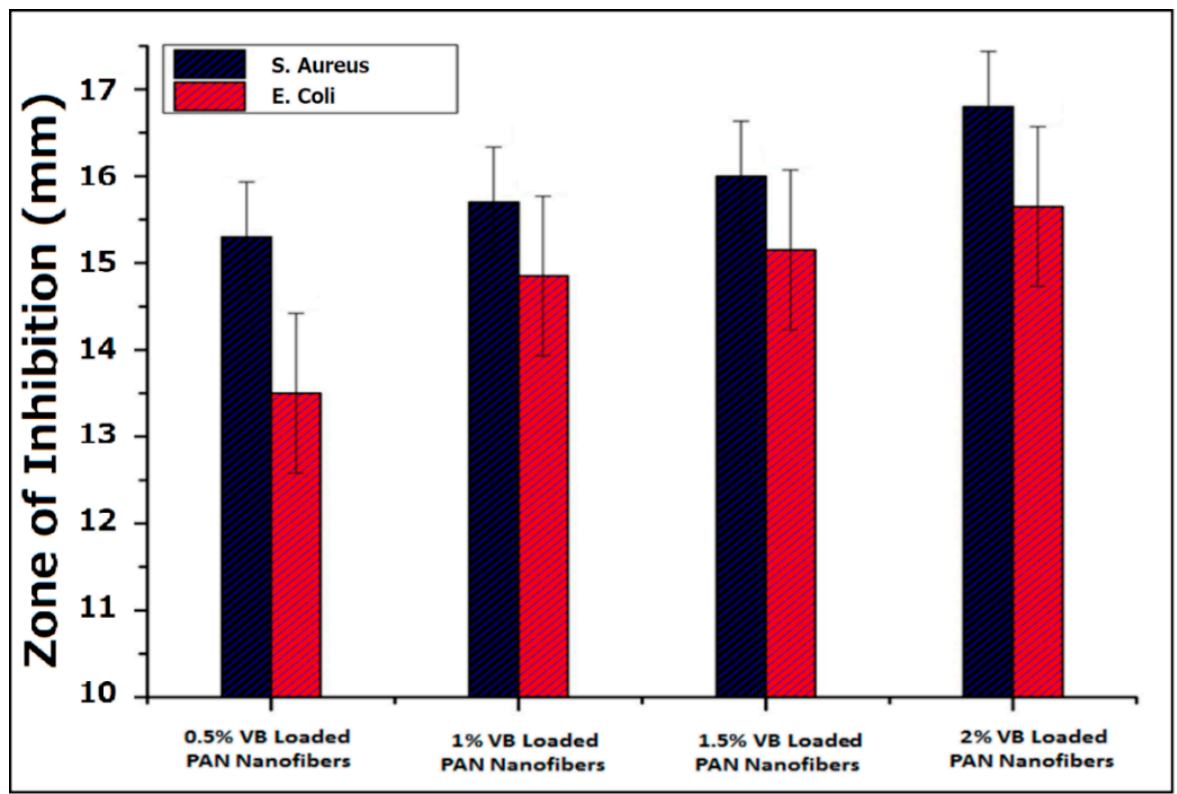

Figure 8. Competitive analysis of the zone of inhibition against S. aureus and E. coli bacteria. 


\subsection{Air Permeability Analysis}

In order to investigate the air permeability of the PAN and VB/PAN nanofibers, an air permeability tester was used. It was confirmed that the air permeability of the VB/PAN nanofibers was slightly reduced, as shown in Figure 9. By increasing the concentration of VB, the air permeability of the nanofibers showed a slight decrease. This was because by increasing the amount of the loading, the diameter of the nanofibers increased, which reduced the air permeability. The advantages of nanofiber masks are the thinness of their fibers, which promotes air permeability whilst maintaining a high rejection of pathogens such as bacteria and viruses due to their small interfiber spaces. The values of air permeability of the resultant nanofibrous membranes with the thickness of $0.35-0.45 \mathrm{~mm}$ were between $74.5-84 \mathrm{~mm} \mathrm{~s}^{-1}$. For the commercial Nano-N95 or the surgical mask, the values were reported to be less than $20 \mathrm{~mm} \mathrm{~s}^{-1}$; thus, the fabricated membranes were much more breathable [29].

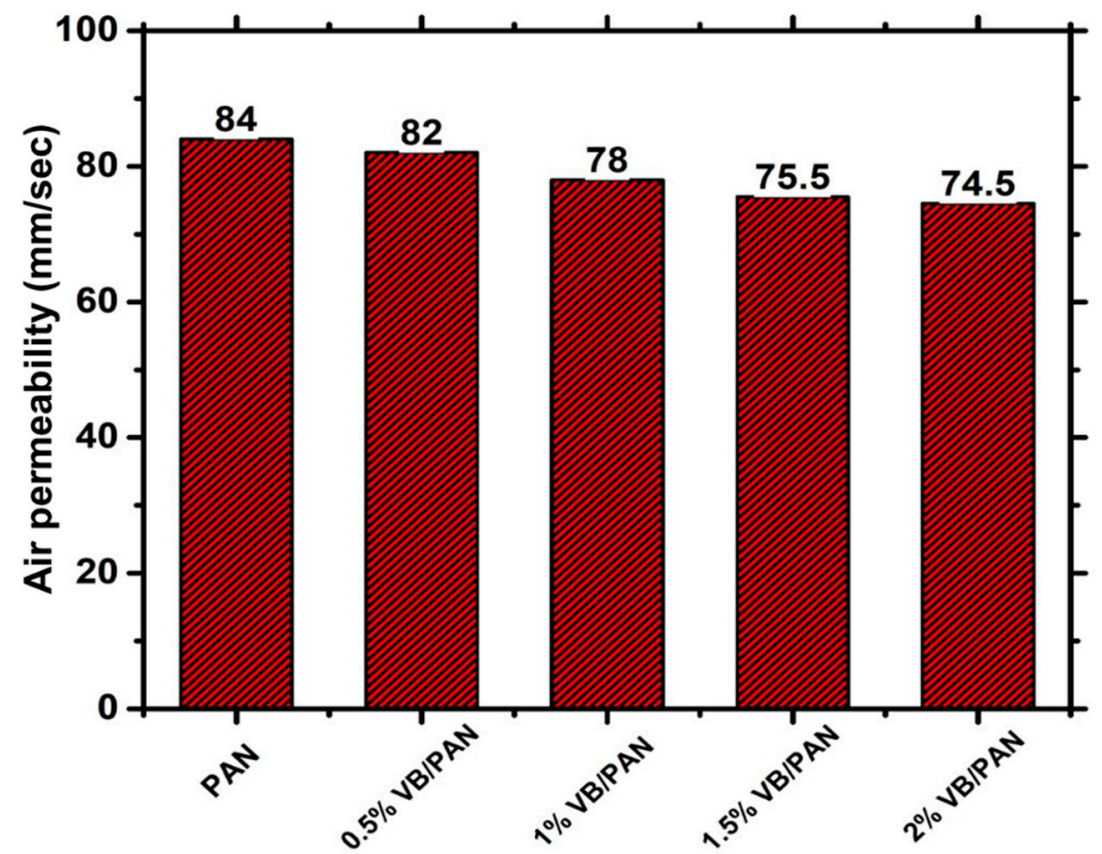

Figure 9. Air permeability of PAN and VB/PAN nanofibers.

\section{Conclusions}

In this study, VB/PAN nanofibers were successfully fabricated with antiviral properties by the electrospinning method. The antimicrobial properties against $E$. coli and $S$. aureus were significantly increased with the higher loading of VB, demonstrating the antibacterial effects of this compound. The four different concentrations of VB material were proved to be successfully incorporated in the PAN nanofibers, confirmed by FTIR and TGA. The resultant nanofiber-based webs that were developed had excellent cell viability and showed great potential for antiviral-mask-based composite nanofibers. It was found that $2 \mathrm{wt} \% \mathrm{VB} / \mathrm{PAN}$ nanofibers had the strongest antibacterial and cell viability properties in comparison to the other concentrations of VB used in the PAN solution for electrospinning.

Author Contributions: Conceptualization, D.-N.P. and M.Q.K.; methodology, M.H. and A.S.; experiment, M.F.A. and A.U.; data curation, A.-T.D. and H.V.-M.; writing-original draft preparation, M.Q.K.; writing—review and editing, D.-N.P.; supervision, I.-S.K.; project administration, A.S.A. and Z.J. All authors have read and agreed to the published version of the manuscript.

Funding: This research received no external funding.

Institutional Review Board Statement: Not applicable.

Informed Consent Statement: Not applicable. 
Conflicts of Interest: The authors declare no conflict of interest.

\section{References}

1. Liu, S.-L.; Saif, L. Emerging Viruses without Borders: The Wuhan Coronavirus. Viruses 2020, 12, 130. [CrossRef] [PubMed]

2. Aydin, O.; Emon, B.; Cheng, S.; Hong, L.; Chamorro, L.P.; Saif, M.T.A. Performance of fabrics for home-made masks against the spread of COVID-19 through droplets: A quantitative mechanistic study. Extreme Mech. Lett. 2020, 40, 100924. [CrossRef]

3. O’Dowd, K.; Nair, K.M.; Forouzandeh, P.; Mathew, S.; Grant, J.; Moran, R.; Bartlett, J.; Bird, J.; Pillai, S.C. Face Masks and Respirators in the Fight against the COVID-19 Pandemic: A Review of Current Materials, Advances and Future Perspectives. Materials 2020, 13, 3363. [CrossRef] [PubMed]

4. Han, G.; Zhou, Y. Possibly critical role of wearing masks in general population in controlling COVID-19. J. Med. Virol. 2020, 92, 1779-1781. [CrossRef] [PubMed]

5. Zhang, Z.; Ji, D.; He, H.; Ramakrishna, S. Electrospun ultrafine fibers for advanced face masks. Mater. Sci. Eng. R Rep. 2021, 143, 100594. [CrossRef]

6. Tcharkhtchi, A.; Abbasnezhad, N.; Seydani, M.Z.; Zirak, N.; Farzaneh, S.; Shirinbayan, M. An overview of filtration efficiency through the masks: Mechanisms of the aerosols penetration. Bioact. Mater. 2021, 6, 106-122. [CrossRef]

7. Phan, D.-N.; Lee, H.; Huang, B.; Mukai, Y.; Kim, I.-S. Fabrication of electrospun chitosan/cellulose nanofibers having adsorption property with enhanced mechanical property. Cellulose 2019, 26, 1781-1793. [CrossRef]

8. Wei, L.; Sun, R.; Liu, C.; Xiong, J.; Qin, X. Mass production of nanofibers from needleless electrospinning by a novel annular spinneret. Mater. Des. 2019, 179, 107885. [CrossRef]

9. Phan, D.-N.; Dorjjugder, N.; Khan, M.Q.; Saito, Y.; Taguchi, G.; Lee, H.; Mukai, Y.; Kim, I.-S. Synthesis and attachment of silver and copper nanoparticles on cellulose nanofibers and comparative antibacterial study. Cellulose 2019, 26, 6629-6640. [CrossRef]

10. Phan, D.-N.; Khan, M.Q.; Nguyen, N.-T.; Phan, T.-T.; Ullah, A.; Khatri, M.; Kien, N.N.; Kim, I.-S. A review on the fabrication of several carbohydrate polymers into nanofibrous structures using electrospinning for removal of metal ions and dyes. Carbohydr. Polym. 2021, 252, 117175. [CrossRef]

11. Pant, B.; Park, M.; Park, S.-J. Drug Delivery Applications of Core-Sheath Nanofibers Prepared by Coaxial Electrospinning: A Review. Pharmaceutics 2019, 11, 305. [CrossRef] [PubMed]

12. Yang, A.; Cai, L.; Zhang, R.; Wang, J.; Hsu, P.-C.; Wang, H.; Zhou, G.; Xu, J.; Cui, Y. Thermal Management in Nanofiber-Based Face Mask. Nano Lett. 2017, 17, 3506-3510. [CrossRef]

13. Phan, D.-N.; Rebia, R.A.; Saito, Y.; Kharaghani, D.; Khatri, M.; Tanaka, T.; Lee, H.; Kim, I.-S. Zinc oxide nanoparticles attached to polyacrylonitrile nanofibers with hinokitiol as gluing agent for synergistic antibacterial activities and effective dye removal. J. Ind. Eng. Chem. 2020, 85, 258-268. [CrossRef]

14. Jatoi, A.W.; Gianchandani, P.K.; Kim, I.S.; Ni, Q.-Q. Sonication induced effective approach for coloration of compact polyacrylonitrile (PAN) nanofibers. Ultrason. Sonochem. 2019, 51, 399-405. [CrossRef]

15. Tebyetekerwa, M.; Xu, Z.; Yang, S.; Ramakrishna, S. Electrospun Nanofibers-Based Face Masks. Adv. Fiber Mater. $2020,2,161-166$. [CrossRef]

16. Ciriminna, R.; Albo, Y.; Pagliaro, M. New Antivirals and Antibacterials Based on Silver Nanoparticles. ChemMedChem 2020, 15, 1619-1623. [CrossRef] [PubMed]

17. Jin, S.Y.; Kim, M.H.; Jeong, Y.G.; Yoon, Y.I.; Park, W.H. Effect of alkaline hydrolysis on cyclization reaction of PAN nanofibers. Mater. Des. 2017, 124, 69-77. [CrossRef]

18. Phan, D.-N.; Dorjjugder, N.; Saito, Y.; Khan, M.Q.; Ullah, A.; Bie, X.; Taguchi, G.; Kim, I.-S. Antibacterial mechanisms of various copper species incorporated in polymeric nanofibers against bacteria. Mater. Today Commun. 2020, 25, 101377. [CrossRef]

19. Zhang, Y.-Z.; Wu, Z.; Pan, G.-L.; Liu, S.; Gao, X.-P. Microporous Carbon Polyhedrons Encapsulated Polyacrylonitrile Nanofibers as Sulfur Immobilizer for Lithium-Sulfur Battery. ACS Appl. Mater. Interfaces 2017, 9, 12436-12444. [CrossRef] [PubMed]

20. Phan, D.-N.; Dorjjugder, N.; Saito, Y.; Taguchi, G.; Lee, H.; Lee, J.S.; Kim, I.-S. The mechanistic actions of different silver species at the surfaces of polyacrylonitrile nanofibers regarding antibacterial activities. Mater. Today Commun. 2019, 21, 100622. [CrossRef]

21. Phan, D.-N.; Dorjjugder, N.; Saito, Y.; Taguchi, G.; Ullah, A.; Kharaghani, D.; Kim, I.-S. The synthesis of silver-nanoparticleanchored electrospun polyacrylonitrile nanofibers and a comparison with as-spun silver/polyacrylonitrile nanocomposite membranes upon antibacterial activity. Polym. Bull. 2020, 77, 4197-4212. [CrossRef]

22. Lee, J.; Yoon, J.; Kim, J.-H.; Lee, T.; Byun, H. Electrospun PAN-GO composite nanofibers as water purification membranes. J. Appl. Polym. Sci. 2018, 135, 45858. [CrossRef]

23. Zhang, C.-L.; Lu, B.-R.; Cao, F.-H.; Yu, Z.-L.; Cong, H.-P.; Yu, S.-H. Hierarchically structured $\mathrm{Co}_{3} \mathrm{O}_{4} @$ carbon porous fibers derived from electrospun ZIF-67/PAN nanofibers as anodes for lithium ion batteries. J. Mater. Chem. A 2018, 6, 12962-12968. [CrossRef]

24. Kharaghani, D.; Khan, M.Q.; Shahrzad, A.; Inoue, Y.; Yamamoto, T.; Rozet, S.; Tamada, Y.; Kim, I.S. Preparation and In-Vitro Assessment of Hierarchal Organized Antibacterial Breath Mask Based on Polyacrylonitrile/Silver (PAN/AgNPs) Nanofiber. Nanomaterials 2018, 8, 461. [CrossRef]

25. Ullah, A.; Ullah, S.; Khan, M.Q.; Hashmi, M.; Nam, P.D.; Kato, Y.; Tamada, Y.; Kim, I.S. Manuka honey incorporated cellulose acetate nanofibrous mats: Fabrication and in vitro evaluation as a potential wound dressing. Int. J. Biol. Macromol. 2020, 155, 479-489. [CrossRef] 
26. Law, K.-Y. Definitions for Hydrophilicity, Hydrophobicity, and Superhydrophobicity: Getting the Basics Right. J. Phys. Chem. Lett. 2014, 5, 686-688. [CrossRef]

27. Ullah, A.; Saito, Y.; Ullah, S.; Haider, K.; Nawaz, H.; Duy-Nam, P.; Kharaghani, D.; Kim, I.S. Bioactive Sambong oil-loaded electrospun cellulose acetate nanofibers: Preparation, characterization, and in-vitro biocompatibility. Int. J. Biol. Macromol. 2021, 166, 1009-1021. [CrossRef] [PubMed]

28. Reidy, B.; Haase, A.; Luch, A.; Dawson, K.A.; Lynch, I. Mechanisms of Silver Nanoparticle Release, Transformation and Toxicity: A Critical Review of Current Knowledge and Recommendations for Future Studies and Applications. Materials 2013, 6, 2295-2350. [CrossRef]

29. Li, Y.; Wong, T.; Chung, J.; Guo, Y.; Hu, J.; Guan, Y.; Yao, L.; Song, Q.; Newton, E. In vivo protective performance of N95 respirator and surgical facemask. Am. J. Ind. Med. 2006, 49, 1056-1065. [CrossRef] [PubMed] 